\title{
Characteristics of variations in the ground magnetic field during substorms at mid latitudes
}

\author{
K. L. Turnbull ${ }^{1}$, J. A. Wild ${ }^{1}$, F. Honary ${ }^{1}$, A. W. P. Thomson ${ }^{2}$, and A. J. McKay ${ }^{2, *}$ \\ ${ }^{1}$ Department of Communication Systems, InfoLab21, Lancaster University, Lancaster, LA1 4WA, UK \\ ${ }^{2}$ British Geological Survey, West Mains Road, Edinburgh, EH9 3LA, UK \\ *now at: Petroleum Geoservices, 10 Bankhead Crossway South, Edinburgh, EH11 4EP, UK
}

Received: 27 March 2009 - Revised: 12 August 2009 - Accepted: 17 August 2009 - Published: 1 September 2009

\begin{abstract}
Substorms are known to cause geomagnetically induced currents (GIC) in power transmission lines through variations in the ground magnetic field. An improved knowledge and understanding of how the different phases of substorms affect the ground magnetic field will ultimately help to better understand how GIC arise. Although usually associated with high latitude power transmission networks, GIC potentially pose a risk to mid latitude networks such as the UK's National Grid. Using a list of substorm expansion phase onsets derived from auroral observations by the IMAGE-FUV satellite, this study examines 553 individual onsets. In order to cover mid latitudes, ground magnetometer data from the UK Sub-Auroral Magnetometer Network (SAMNET) are exploited. These high time resolution ( $5 \mathrm{~s}$ ) data are used to study the ground magnetic field for an hour after onset, in particular the time derivative of the horizontal magnetic field, $\boldsymbol{H}$. The data covers the period from 2000 to 2003 (just after solar maximum). Results are compared with a previous study of magnetic field variations at higher latitudes, using data with a much lower (1 min) cadence during substorms identified from geomagnetic indices during a period just after solar minimum.
\end{abstract}

Keywords. Geomagnetism and paleomagnetism (Rapid time variations) - Ionosphere (Mid-latitude ionosphere) Magnetospheric physics (Storms and substorms)

\section{Introduction}

Substorms are rapid reconfigurations of the terrestrial magnetosphere resulting from the release of solar wind energy and momentum stored in the Earth's magnetospheric tail. This energy is primarily transferred into the magnetosphere

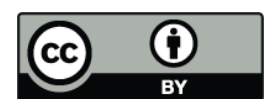

Correspondence to: K. L. Turnbull (k.turnbull1@lancaster.ac.uk) from the interplanetary magnetic field (IMF) and solar wind via magnetic reconnection at the dayside magnetopause. As such, substorms represent one of the fundamental modes of global energy circulation and magnetic flux transport in the geospace environment (Cowley et al., 2003). Following dayside reconnection, magnetic flux is added to the tail lobes causing the magnetic flux density in the tail to increase. This stored energy is eventually released in an explosive fashion and the magnetosphere undergoes rapid reconfiguration. The process of gradual energy storage followed by a sudden release are usually referred to as the substorm growth and the expansion phase, respectively. Substorms can occur at anytime but are observed more frequently during high solar activity (Baumjohann et al., 1996).

During the expansion phase, magnetospheric currents are diverted through the Earth's ionosphere, resulting in large disturbances in the magnetic field observed at the ground. These rapid fluctuations in the ground magnetic field also induce electric fields in the Earth's surface. Magnetic and electric fields in the surface of the Earth are related by

$$
\frac{E}{B}=Z
$$

where $\boldsymbol{Z}$ is the impedance of the Earth. $\boldsymbol{Z}$ in a particular area depends on local conditions, such as conductivity and magnetic permeability of the ground. The depth at which the magnetic fields can penetrate the ground is also important as the average conductivity along this depth will affect the electric field (Boteler, 1994). Therefore the geology of the UK and the magnetic field variations will both have an effect on the induced electric fields in the surface.

As a consequence of magnetic field variations on the surface of the Earth, an electromotive force is created between earthed points of a conductor such as those in a power transmission network, causing geomagnetically induced currents (GIC) to flow along the network (e.g. Lehtinen and Pirjola, 1985). GIC are quasi-dc when compared

Published by Copernicus Publications on behalf of the European Geosciences Union. 
to power transmission frequencies of $50-60 \mathrm{~Hz}$, (Molinski, 2002; Kappenman, 2007). GIC enter and exit a power transmission network through the earthed transformers at substations possibly causing transformer saturation that can damage the transformer and disrupt the entire power network. In 1989 a geomagnetic disturbance caused the Hydro-Québec power system to fail. At a cost of approximately $\$ 13$ million, it is a perfect example of the risk posed to power networks (Bolduc, 2002). In 2003 large geomagnetic storms also caused disruption to power networks including the Swedish power system where the city of Malmo experienced blackout for 20 to $50 \mathrm{~min}$. In 2000 a GIC of about $300 \mathrm{~A}$ was recorded in Sweden, the largest measured GIC value ever reported (as far as we know) (Wik et al., 2008).

Any type of geomagnetic disturbance may have an impact on a power transmission network. The scale and size of the damage to a particular power transmission network depend on the magnitudes of GIC in different parts of the system and on several technical matters, such as transformer types used, configuration of the network and load situation. Local geological conditions also influence GIC production. When modelling GIC production in a power transmission network there are essentially two factors to consider. First, the electric field in the vicinity of the power transmission network is calculated as though the network was absent, this involves knowledge of magnetospheric-ionospheric currents and of the Earth's conductivity structure. Second, this primary field is used to calculate currents produced in the network, so details of the power transmission network such as line and transformer resistances, topology and configuration of the network are also required (Lehtinen and Pirjola, 1985).

Although the UK is located at mid latitudes and is therefore not considered to be exposed to the risks posed by GIC, past events have proved this not to be the case. The UK national grid has experienced problems as a result of GIC such as large reactive power swings and transformer failures. Although there have been no severe consequences for customers, a prolonged geomagnetic disturbance may cause wider disruption (Erinmez et al., 2002). The Scottish power system has also experienced similar problems with, for example, GIC levels at monitoring sites rising to approximately 40 A during the Halloween storm of 30 October 2003. During this event the surface electric field was 50 times greater than quiet time levels (Thomson et al., 2005).

Other mid latitude countries are also investigating the GIC risk to their power transmission systems, including South Africa which is especially at risk because of the long transmission lines involved (Ngwira et al., 2008). Failures and damage of 15 transformers by internal heating, in the high voltage South African main transmission system in November 2003 have been attributed to the production of GIC as a result of geomagnetic disturbances (Gaunt and Coetzee, 2007; Kappenman, 2005). Measurements of GIC at this time closely resembled the results of a model of GIC production by geomagnetic events in the South African network (Koen,
2002). This demonstrates the potential usefulness of a GIC model to a real power transmission network.

Since direct measurement of the electric field at the Earth's surface is not ideal over such a large area, the characteristics of the magnetic field produced by the substorm are used instead. Studies of the characteristics of ground magnetic field variations have tended to focus on higher latitude areas such as Fennoscandia, by looking at the time derivative of the horizontal ground magnetic field, $d \boldsymbol{H} / d t$ (Viljanen et al., 2001). In particular, a study by Viljanen et al. (2006) on the relationship between substorms and $\boldsymbol{H}$, using the International Monitor for Auroral Geomagnetic Effects (IMAGE) network concludes that the largest values of $d \boldsymbol{H} / d t$ appear soon after the expansion phase begins, although many events have larger values at later times. The size of $\max |d \boldsymbol{H} / d t|$ increases with increasing latitude equatorward of the auroral oval, poleward of which it decreases. Furthermore, storm time substorms can double the size of $\max |d \boldsymbol{H} / d t|$ at all latitudes compared to non-storm time substorms. It was also found that although $\boldsymbol{H}$ is greatly influenced by the electrojet, $d \boldsymbol{H} / d t$ is more susceptible to the effects of smaller scale ionospheric features. The events looked at by Viljanen et al. (2006) occurred just after sunspot minimum and magnetometer data were exploited to detect the substorm onset and analyse $\boldsymbol{H}$, between magnetic latitudes $56^{\circ} \mathrm{N}$ and $75^{\circ} \mathrm{N}$.

This study aims to characterise the magnetic field behaviour over the UK during a substorm. This is done by exploiting magnetometer data, including mid latitude magnetometer sites, to analyse the response of the ground magnetic field to substorms, however a method other than ground magnetometry is used to identify substorm onsets. This study also uses ground magnetometer measurements recorded at a higher sampling rate than the Viljanen et al. (2006) study and use data from a different period in the solar cycle. The results of this study will aid GIC modelling in the UK's power transmission network.

\section{Data and method}

Since the effect of substorms on GIC production is best characterised by analysing the variation of $\boldsymbol{H}$ sensed at the ground, detection of substorm onset is established by an independant method. This is achieved by using the list produced by Frey et al. (2004) of substorm onset times and locations determined by the IMAGE-FUV satellite. Onset time and location are found by studying images from the FUV imager which observes aurora in ultra violet light, and looking for particular behaviours (Frey et al., 2004):

- a clear local brightening of the aurora

- expansion of the aurora to the poleward boundary of the auroral oval and spreading azimuthally in local time for at least $20 \mathrm{~min}$ 


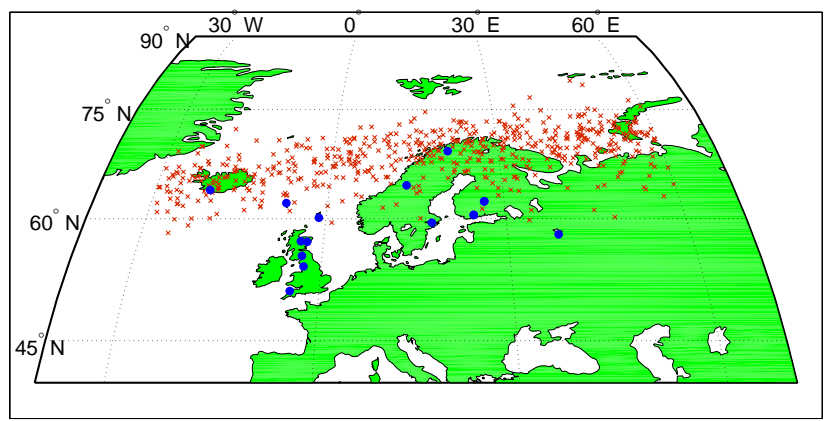

Fig. 1. Map showing the location of SAMNET stations used in this study (blue circles), and the location of the 553 substorm onsets (red crosses) as determined by the IMAGE-FUV satellite. (Geographic latitudes).

- at least $30 \mathrm{~min}$ had passed since the previous substorm onset, this is to eliminate events that did not develop into full substorms

Thus the IMAGE-FUV mission produced substorm onset details from 2000 to 2005 from all over the globe. This list of events is reduced to only substorms that happen at a time and location suitable for scrutiny by the UK-Sub-Auroral Magnetometer Network (SAMNET), as it covers a range of mid to high latitudes including those that cover the UK. Since the peak time for substorm onset to occur is at 23:00 MLT, the list by Frey et al. (2004) was limited to events between 18:00 MLT and 04:00 MLT and between latitudes of $25^{\circ} \mathrm{N}$ and $90^{\circ} \mathrm{N}$, and longitudes of $30^{\circ} \mathrm{W}$ and $60^{\circ} \mathrm{E}$. This resulted in a list of 553 substorm onsets that span 2000 to 2003 which is just after a solar cycle maximum. Figure 1 shows the locations of SAMNET stations and substorm onsets included in this study.

The substorm onsets are divided into those that occur during storm time conditions ( $D_{s t}<-40 \mathrm{nT}, 83$ subtorms) and non-storm time conditions $\left(D_{s t}>-40 \mathrm{nT}, 470\right.$ substorms), the cut off value of $-40 \mathrm{nT}$ is consistent with Viljanen et al. (2006). The $D_{s t}$ used is the daily mean value of $D_{s t}$ for the day at which the substorm occurs taken from NOAA National Geophysical Data Center (NGDC, 2009).

The time derivative of the horizontal ground magnetic field $d \boldsymbol{H} / d t$ is the major contributor to GIC production (Viljanen et al., 2006), so for each substorm onset an hour's data are needed in order to investigate the effect of substorms on $\boldsymbol{H}$. SAMNET data used here have a time resolution of $5 \mathrm{~s}$ and only stations that had no interruptions during the required one hour period are used. $d \boldsymbol{H} / d t$ is calculated as the difference between successive readings divided by the sampling rate (Viljanen et al., 2001).

This study is in contrast to a similar study by Viljanen et al. (2006) on the relationship between substorm characteristics and $\boldsymbol{H}$ which uses IMAGE to both pinpoint substorm onset, and analyse $\boldsymbol{H}$. Other differences include; range of

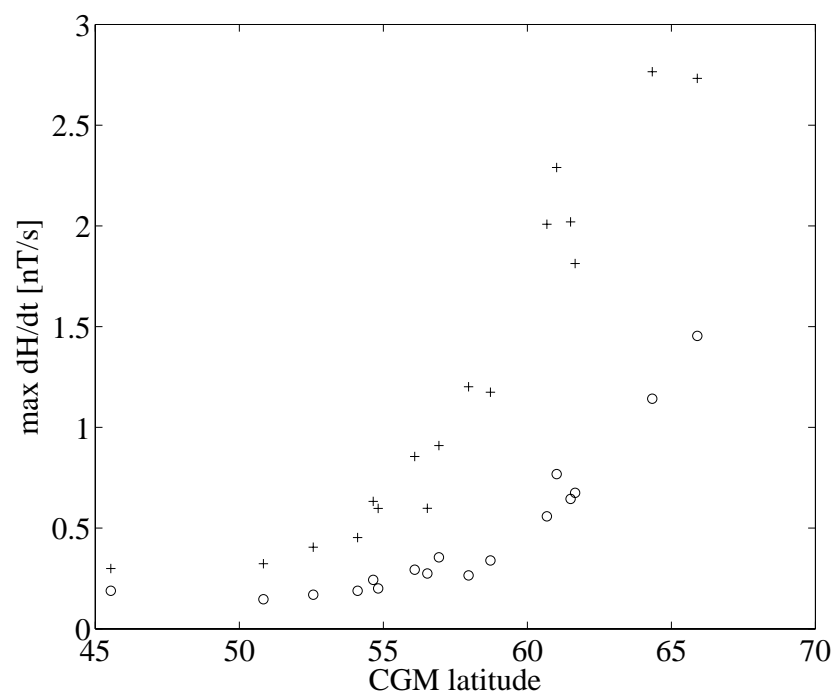

Fig. 2. The mean $\max |d \boldsymbol{H} / d t|$ at each SAMNET station against the corrected geomagnetic latitude. The crosses are storm time substorm onsets ( 83 events), and circles are the non-storm time onsets (470 events).

latitude, Viljanen et al. (2006) covers CGM latitudes from $55^{\circ} \mathrm{N}$ to $75^{\circ} \mathrm{N}$ which is not low enough to adequately cover the UK; and sampling rate, Viljanen et al. (2006) has a $1 \mathrm{~min}$ time resolution on its magnetic data. The substorms investigated by Viljanen et al. (2006) occur just after a sunspot minimum, (1997-1999), whereas this study examines substorms occurring just after solar maximum (2000-2003). The differences and similarities between these studies will therefore improve understanding of the relationship between substorms and variations in $\boldsymbol{H}$ at the Earth's surface.

\section{Results}

In Fig. 2 the mean value of $\max |d \boldsymbol{H} / d t|$ of all substorms calculated at each SAMNET station is shown against the corrected geomagnetic (CGM) latitude of the SAMNET stations. The plot shows that average $\max |d \boldsymbol{H} / d t|$ increases with latitude for storm time and non-storm time substorm onsets. It also shows that at all the stations the storm time values are greater (approximately double) than the non-storm time values, even at the lowest latitudes. The corresponding plot by Viljanen et al. (2006, Fig. 2) also shows an increase with latitude up to $68^{\circ} \mathrm{N}$ and the doubling of values in storm-time conditions.

The response time of the ground magnetic field to substorm onset is an important consideration. For each event, the time at which the maximum value of $d \boldsymbol{H} / d t$ occurs, from $20 \mathrm{~min}$ before onset and $1 \mathrm{~h}$ after, is recorded. Then for each SAMNET station a histogram is plotted showing how many maxima occurred in each 1-min bin of the sampled data. 


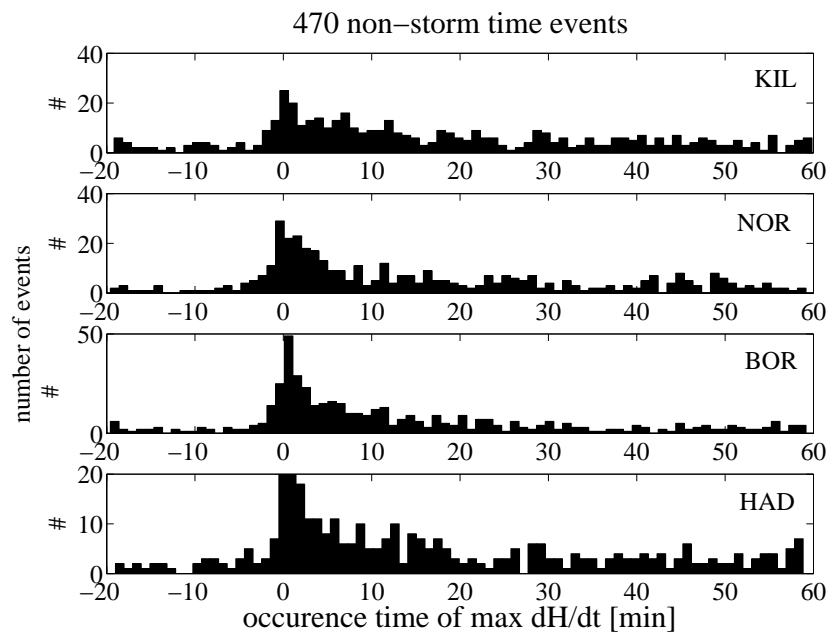

Fig. 3. Times at which $\max |d \boldsymbol{H} / d t|$ occurs at SAMNET stations, KIL (Kilpisjarvi, 65.9 ${ }^{\circ} \mathrm{N}$ ), NOR (Nordii, 61.5 ${ }^{\circ} \mathrm{N}$ ), BOR (Borok, $54.11^{\circ} \mathrm{N}$ ), HAD (Hartland, $50.99^{\circ} \mathrm{N}$ ), during non-storm time. Substorm onset occurs at $0 \mathrm{~min}$. CGM latitudes.

Figure 3 shows these results for four SAMNET stations over a range of latitudes using only non-storm time data. All four panels in Fig. 3 have a peak in the first minute after substorm onset and then a long tail which is as expected from such a complex process; this is also the case for the other SAMNET stations in this study. For some events larger $d \boldsymbol{H} / d t$ seem to occur in the $20 \mathrm{~min}$ before onset, however these values could be the result of two substorms occuring within a short time of each other or some other activity not associated with the substorm. Even though there are some values in the $20 \mathrm{~min}$ period before onset, there is still a clear peak at the time onset apears. The northernmost station in the figure is Kilpisjarvi and seems to show some greater disruption than the others in the later times. This could possibly be due to its proximity to the auroral oval. Figure 4 presents the same analysis, for storm time events. These plots seem to show even more disruption, particularly at Kilpisjarvi, again this could in part be due to the proximity of the auroral oval which tends to be at lower latitudes during storm time but also there is the effect of the small data sample: storm time substorms are only $15 \%$ of the total substorms used in this study. Even so, there is a peak in the first minute after substorm onset and a long tailed distribution.

The most probable time for $\max |d \boldsymbol{H} / d t|$ to occur after substorm onset is the mode, which is calculated for each SAMNET station and plotted against CGM latitude for nonstorm time and storm time separately in Fig. 5. The nonstorm time modes almost all occur in less than a minute whereas the storm time modes occur within 2 min. There also appear to be two outliers in the storm time data, the outlier at the lower latitude is a result of a small data sample for that particular station, however the higher latitude outlier has

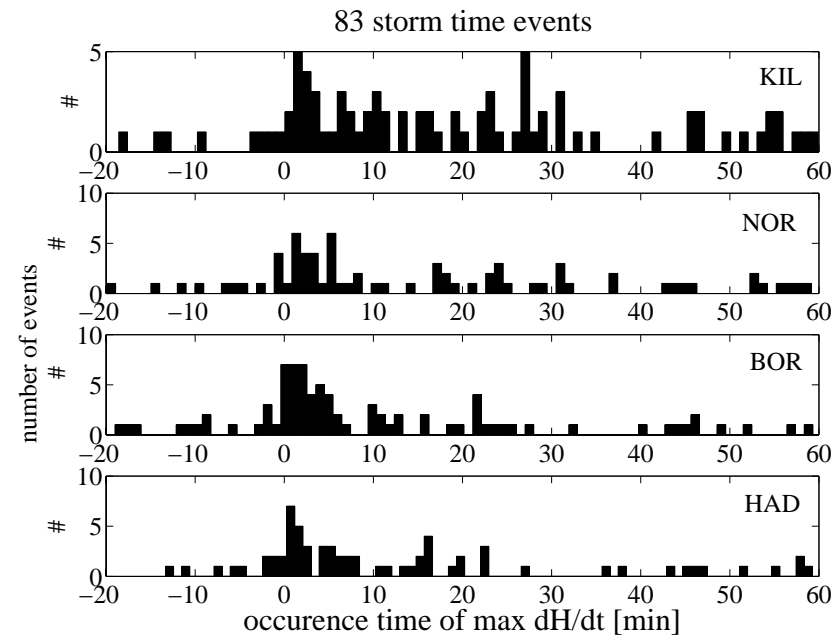

Fig. 4. Times at which $\max |d \boldsymbol{H} / d t|$ occurs at SAMNET stations, KIL (Kilpisjarvi, 65.9 $\mathrm{N}$ ), NOR (Nordii, 61.5 ${ }^{\circ} \mathrm{N}$ ), BOR (Borok, $54.11^{\circ} \mathrm{N}$ ), HAD (Hartland, 50.99 $\mathrm{N}$ ), during storm-time. Substorm onset occurs at $0 \mathrm{~min}$. CGM latitudes.

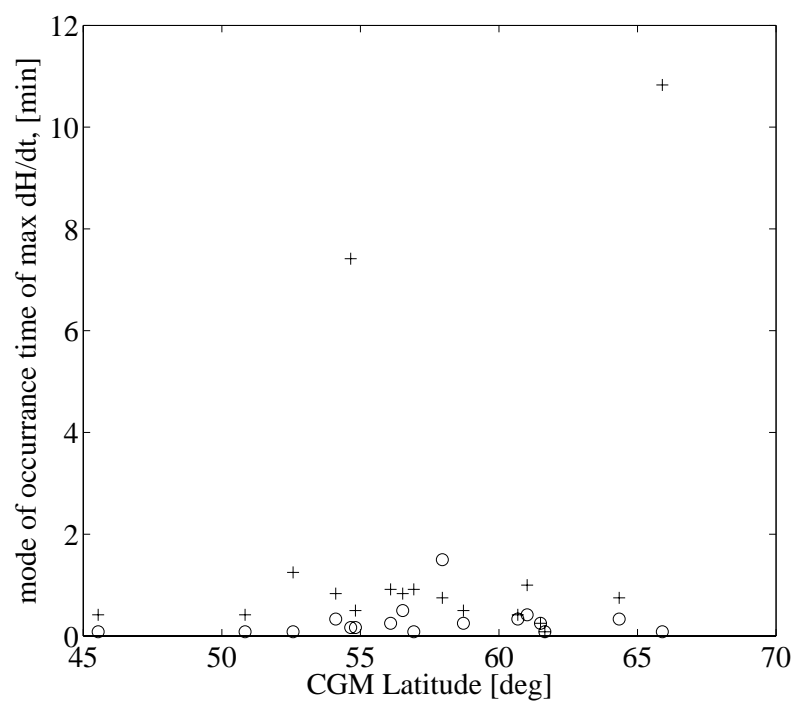

Fig. 5. Mode of occurrence of $\max |d \boldsymbol{H} / d t|$ times against CGM latitude. Crosses are storm time substorm onsets (83 events), and the circles are non-storm time substorm onsets (470 events).

a large data set. When Fig. 5 is compared to Viljanen et al. (2006, Fig. 5), which also shows the most probable time of $\max |d \boldsymbol{H} / d t|$ after onset over a range of latitudes, it can be seen that in storm time conditions the peak times start to increase above $5 \mathrm{~min}$ at latitudes over $60^{\circ} \mathrm{N}$, in the non storm time case this does not happen until latitudes above $70^{\circ} \mathrm{N}$. So it is possible that in Fig. 5 the storm time value at $66^{\circ} \mathrm{N}$ is indicating the effect of the auroral oval on the occurrence times of $\max |d \boldsymbol{H} / d t|$, however data for higher latitudes would be needed to confirm this. 


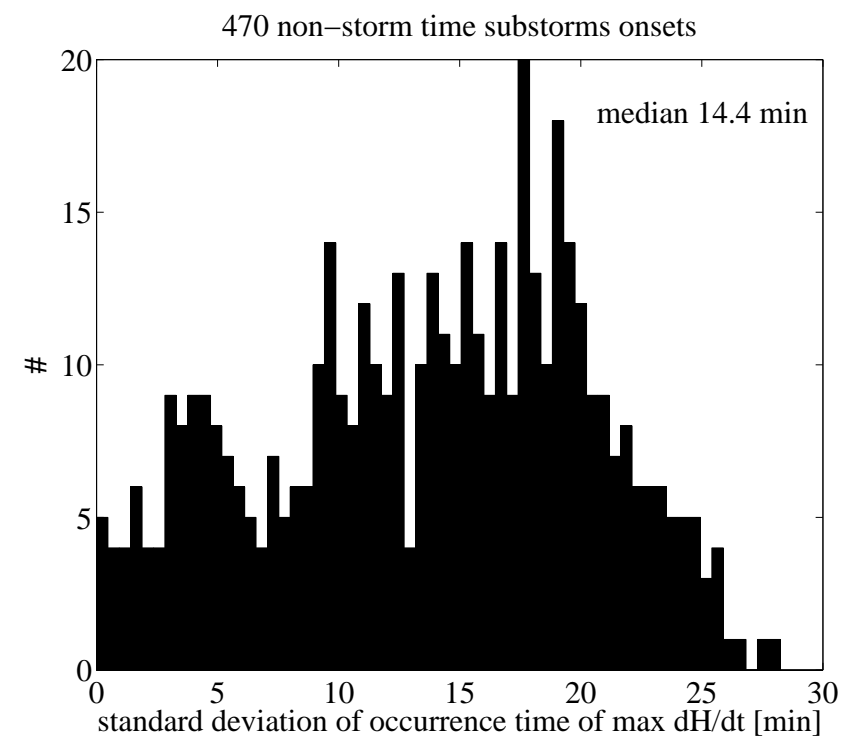

Fig. 6. Histogram showing the standard deviation of times of occurrence of $\max |d \boldsymbol{H} / d t|$ for each non-storm time event, 470 onsets.

Substorms are large scale events and can cause large $\max |d \boldsymbol{H} / d t|$ at a range of sites, but the coincidence of the occurrence of $\max |d \boldsymbol{H} / d t|$ at multiple sites is significant to the development of GIC in power transmission networks. It is therefore useful at this point to look at the standard deviation of the occurrence time of $\max |d \boldsymbol{H} / d t|$ at the range of SAMNET stations for each event. Shown in Fig. 6 is the non-storm time histogram of standard deviation of the time at which $\max |d \boldsymbol{H} / d t|$ occurs at SAMNET sites for each event. There is a broad distribution with a peak around $20 \mathrm{~min}$, the median is $14.4 \mathrm{~min}$. Figure 7 is the same plot but for the storm time onsets, again there is a broad range, with a peak around the $20 \mathrm{~min}$ mark, the median is $15.1 \mathrm{~min}$.

As $\max |d \boldsymbol{H} / d t|$ is not usually a result of the largest $\boldsymbol{H}$ it is also useful to know how much of a correlation there is between the two values. So far this study has only been considering $d \boldsymbol{H} / d t$ and therefore it has not been necessary to consider the actual value of $\boldsymbol{H}$. This can be significantly different from one site to another due to the natural background $\boldsymbol{H}$ and therefore $\boldsymbol{H}$ values at different sites are not directly comparable. In order to compare values of $\boldsymbol{H}$ at the range of SAMNET sites, data for $24 \mathrm{~h}$ before and after each substorm onset time (i.e. a $48 \mathrm{~h}$ period) are examined and the median value taken for each event at each site. This is then subtracted from $\boldsymbol{H}$ at that site. Now data for each event at all sites can be compared by using $|\boldsymbol{H}|$ (absolute median subtracted $\boldsymbol{H}$ ). The largest $\max |d \boldsymbol{H} / d t|$ for each event and its corresponding value of $|\boldsymbol{H}|$ (i.e. the value of $|\boldsymbol{H}|$ as $\max |d \boldsymbol{H} / d t|$ is achieved) are plotted against each other in Fig. 8 and 9. The non-storm time events are plotted in Fig. 8 and show that $\max |d \boldsymbol{H} / d t|$ does in general increase with increasing $|\boldsymbol{H}|$,

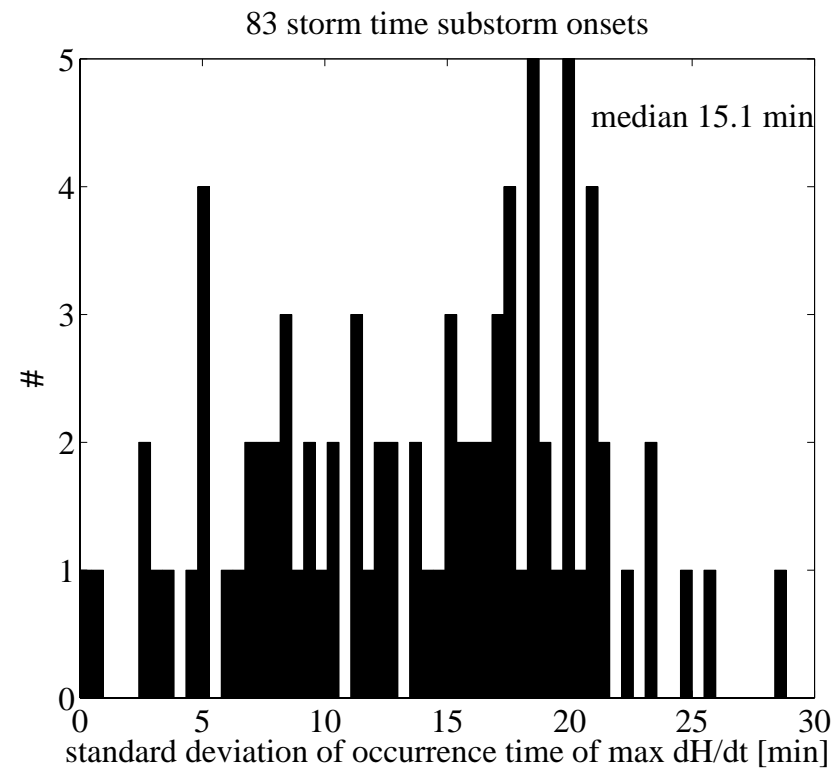

Fig. 7. Standard deviation of time of occurrence of $\max |d \boldsymbol{H} / d t|$ for each storm time event, 83 onsets.

but the correlation is only 0.5988 . The corresponding value of $\max |d \boldsymbol{H} / d t|$ for a given value of $|\boldsymbol{H}|$ can vary by as much as $\pm 8 \mathrm{nT} / \mathrm{s}$. The correlation for storm time events is 0.5886 and also shows a general increase in $\max |d \boldsymbol{H} / d t|$ with $|\boldsymbol{H}|$, however there is considerable variation.

Since the direction of the magnetic field may be important to the susceptibility of a power transmission network to GIC, the directions of $d \boldsymbol{H} / d t$ for $\max |d \boldsymbol{H} / d t|$ and of the corresponding $\boldsymbol{H}$ must also be examined. Using the same values as in Fig. 8 and 9, the largest $\max |d \boldsymbol{H} / d t|$ vectors are plotted on a compass diagram enabling the magnitude and direction of the largest $\max |d \boldsymbol{H} / d t|$ for each event to be compared. The same is also done for the corresponding value of median subtracted $\boldsymbol{H}$. Figure 10, shows four compass plots with magnetic north pointing to the top of the page and magnetic east to the right. The top two plots show the vectors of the largest $|d \boldsymbol{H} / d t|$ for each event and the bottom two plots show the corresponding value of median subtracted $\boldsymbol{H}$. Immediately obvious is the difference in the amount of data available for non-storm time and storm time events. The plots for $\max |d \boldsymbol{H} / d t|$ in both non-storm and storm time plots show that changes in the field occur in all directions with a range of magnitudes up to about $20 \mathrm{nT} / \mathrm{s}$. The corresponding values of median subtracted $\boldsymbol{H}$ tend to mostly be directed to the south, non-storm time values reach up to $750 \mathrm{nT}$. Storm time values can reach over $1000 \mathrm{nT}$ and about all of them are directed southwards. The southward polarisation of median subtracted $\boldsymbol{H}$ is to be expected since it corresponds to a westward current over SAMNET. The range of direction for $\max |d \boldsymbol{H} / d t|$ suggests that it is not necessarily the westward 


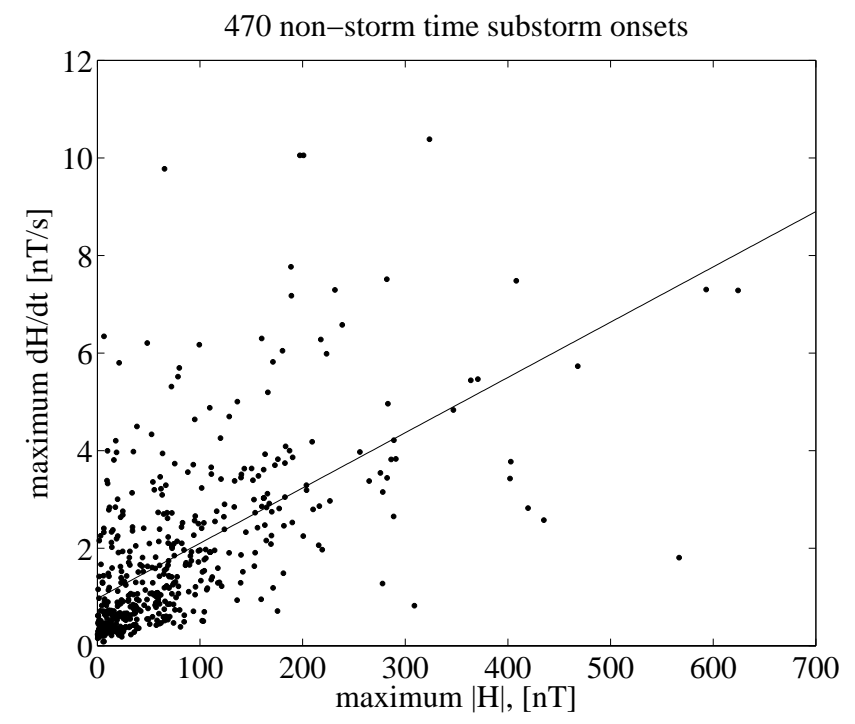

Fig. 8. Plot of $|\boldsymbol{H}|$ against corresponding largest $\max |d \boldsymbol{H} / d t|$ for 470 non-storm time substorms. The line is the linear correlation.

current that governs the behaviour of the rapid variations in $\boldsymbol{H}$. Instead, smaller scale structures in the ionosphere may play an important role.

\section{Comparisons and conclusions}

This study focuses on the time derivative of the horizontal ground magnetic field as this is the key value when considering the generation of GIC from substorms (Viljanen et al., 2001). In particular the different characteristics in storm time and non-storm time substorms is of interest. In order to keep the analysis of $\boldsymbol{H}$ separate from the detection of substorm onset, a list of substorm onsets produced by the IMAGEFUV satellite (Frey et al., 2004) is used to find substorms that occurred at a time and place suitable for SAMNET; consequently all substorms occurred just after solar maximum. The substorms are then divided into non-storm time and storm time substorms.

These are key differences to a similar study by Viljanen et al. (2006) which was carried out using the IMAGE magnetometer network (geographic latitudes between $58^{\circ} \mathrm{N}$ and $79^{\circ} \mathrm{N}$ ) to detect substorm onset and analyse $\boldsymbol{H}$ between 1997 and 1999 (just after solar cycle minimum) with a time resolution of $1 \mathrm{~min}$.

The mean of $\max |d \boldsymbol{H} / d t|$ increases with CGM latitude up to $66^{\circ} \mathrm{N}$ and storm time values are double non-storm time values even at low CGM latitudes of $45^{\circ} \mathrm{N}$ shown in Fig. 2, essentially meaning that during storm time conditions lower CGM latitude sites experience average max $|d \boldsymbol{H} / d t|$ levels similar to sites approximately $5^{\circ}$ higher during non-storm times.

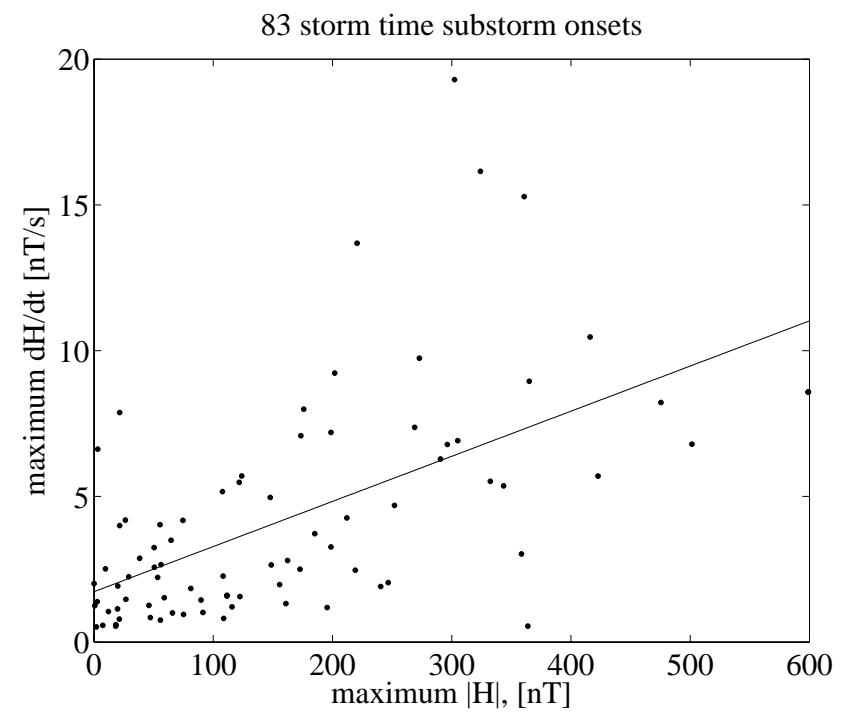

Fig. 9. Plot of $|\boldsymbol{H}|$ against corresponding largest $\max |d \boldsymbol{H} / d t|$ for 83 storm time substorms. The line is the linear correlation.

All latitudes show a peak occurrence time of $\max |d \boldsymbol{H} / d t|$ in the first minute after onset for non-storm time substorms, with a long distribution tail. The similar study by Viljanen et al. (2006) shows a similar feature but the peaks occur around 5 min after onset. As Figs. 3 and 4 show there is some activity before onset occurs but a clear peak at substorm onset time. Since a main difference between these two studies is the higher sampling rate of the SAMNET data we have synthesised 1 min SAMNET data to match that of the Viljanen et al. (2006) study and the same analysis performed. The results still produce a peak in the first minute after substorm onset, so there is a reason for the difference in the studies other than data sampling rate. This study uses IMAGE-FUV observation of auroral brightening to determine onset (with a time resolution of $\sim 2 \mathrm{~min}$ ) while the paper by Viljanen et al. (2006) uses geomagnetic indices which have comparable uncertainty. Studies into the timings of substorm onset indicators, e.g., Rae et al. (2009) highlight the difficulty in determining precise onsets times. Since each method has its own inaccuracy and since the physics of substorm formation and development is still being debated, substorm onset time is somewhat subjective. For this study and the study by Viljanen et al. (2006) it seems that the differences in pinpointing substorm onset and the time resolutions and accuracies of the methods used may be the cause of the discrepancy in $\max |d \boldsymbol{H} / d t|$ occurrence time, and are unlikely to be a result of physical characteristics of mid latitude substorms.

While there is some correlation between corresponding values of $|\boldsymbol{H}|$ and $\max |d \boldsymbol{H} / d t|$, the large range $( \pm 2 \mathrm{nT} / \mathrm{s}$ at low $|\boldsymbol{H}|$ and up to $\pm 8 \mathrm{nT} / \mathrm{s}$ at larger $|\boldsymbol{H}|)$ suggests that a large $\max |d \boldsymbol{H} / d t|$ can be produced without an initially high $|\boldsymbol{H}|$. There is little difference between the correlations for 


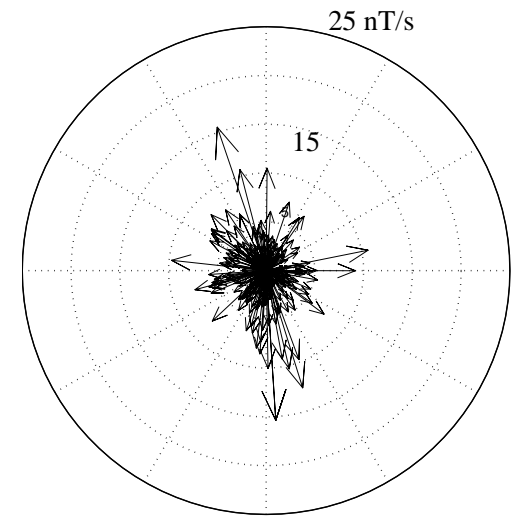

largest max $|d \boldsymbol{H} / d t|$ vectors, non-storm time substorms

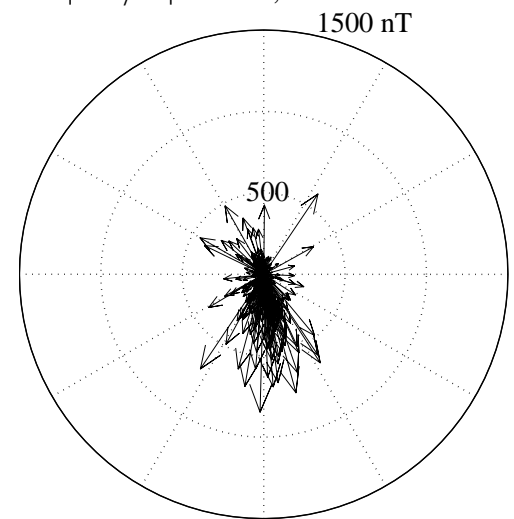

median subtracted $\boldsymbol{H}$ vectors, non-storm time substorms

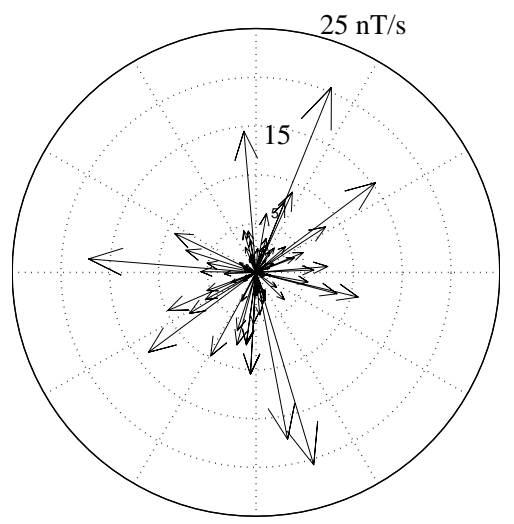

largest max $|d \boldsymbol{H} / d t|$ vectors, storm time substorms

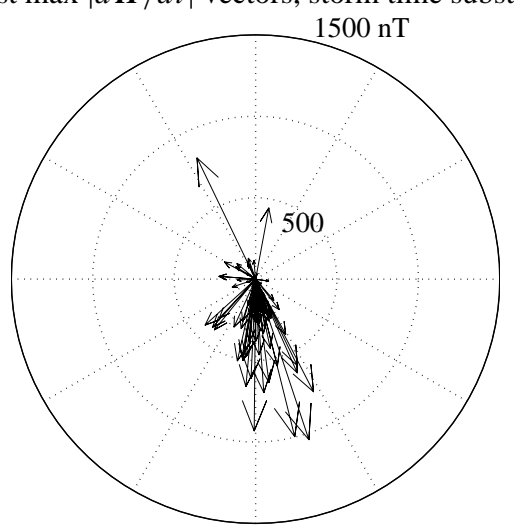

median subtracted $\boldsymbol{H}$ vectors, storm time substorms

Fig. 10. Top figures are the largest $\max |d \boldsymbol{H} / d t|$ vectors for the maximum site, left $=$ non-storm time $(469$ substorms $)$, right $=$ storm time $(83$ substorms). Bottom figures are the simultaneous median subtracted $\boldsymbol{H}$ vectors, left $=$ non-storm time $(466$ substorms $)$, right $=$ storm time $(81$ substorms). (Several outliers were removed in order to be able to display the result clearly. Magnetic north is to the top of the page and east to the right.)

non-storm and storm time onsets indicating that the relationship of $\max |d \boldsymbol{H} / d t|$ and $|\boldsymbol{H}|$ is not affected by storm time conditions.

In Fig. 10, $\max |d \boldsymbol{H} / d t|$ vectors are scattered in all directions and larger values occur in storm time conditions. The corresponding values for median subtracted $\boldsymbol{H}$ are mostly directed to the south which indicates their connection to the westward electrojet. The distribution of $\max |d \boldsymbol{H} / d t|$ suggests that short term changes of the field are influenced by other ionospheric events. These results agree with Viljanen et al. (2006, Fig.8).

Although this study uses substorms that are detected independently of $\boldsymbol{H}$ measurements and with a higher time resolution and at a different point in the sunspot cycle many of the results agree with the similar study by Viljanen et al. (2006). These similarities suggest the differences between the two studies do not impact the results i.e. the basic characteristics of the ground magnetic field during substorms are not affected by the difference in the stages of the solar cycle, data sampling rate, method of determining onset, or loca- tion of study. Differences between solar cycle phase do not produce differences in the results suggesting that substorm characteristics do not vary with the solar cycle. However this study and that of Viljanen et al. (2006) do not cover all phases of a solar cycle and a future study examining substorm characteristics through all phases over many cycles will be needed to determine if there is any effect. However during active phases of the solar cycle, storm time conditions that are expected to effect the ground magnetic field are more likely, doubling the mean $\max |d \boldsymbol{H} / d t|$ from those during non-storm time conditions (as shown in Fig. 2).

With respect to modelling GIC production in a power transmission network, the information gained in this paper will be used to construct model magnetic fields with which to test GIC models. Of particular interest is the response of a power transmission network to a range of field orientations and variations with time as well as simultaneity of large $d \boldsymbol{H} / d t$ over the network. This present study will prove useful in this endeavour. 
Acknowledgement. The Sub-Auroral Magnetometer Network data (SAMNET) is operated by the Department of Communication Systems at Lancaster University (UK) and is funded by the Science and Technology Facilities Council (STFC). Data from the IMAGE stations Kilpisjarvi, Hankasalmi, Oulujarvi, Uppsala and Nurmijarvi (after 2002) data are provided courtesy of the Finnish Meteorological Institute, the University of Oulu and the Geological Survey of Sweden. Lerwick, Hartland and Eskdalemuir data are provided courtesy of the British Geological Survey (NERC). K. L. Turnbull is supported by an EPSRC CASE studentship, co-funded by the British Geological Survey.

Topical Editor I. A. Daglis thanks two anonymous referees for their help in evaluating this paper.

\section{References}

Baumjohann, W., Kamide, Y., and Nakamura, R.: Substorms, Storms, and the Near Earth Tail, J. Geomag. Geoelectr., 48, 117185, 1996.

Bolduc, L.: GIC observations and studies in the Hydro-Québec power system, J. Atmos. Terr. Phys., 64, 1793-1802, 2002.

Boteler, D. H.: Geomagnetically Induced Currents: Present knowledge and future research., IEE Transactions on Power Delivery, 9, 1994.

Cowley, S. W. H., Davies, J. A., Grocott, A., Khan, H., Lester, M., McWilliams, K. A., Milan, S. E., Provan, G., Sandholt, P. E., Wild, J. A., and Yeoman, T. K.: Solar wind-magnetosphereionosphere interactions in the Earth's plasma environment., Phil. Trans. A, 361, 113-126, 2003.

Erinmez, I. A., Kappenman, J. G., and Radasky, W. A.: Management of the geomagnetically induced current risks on the national grid company's electric power transmission system, J. Atmos.Terr. Phys., 64, 743-756, 2002.

Frey, H. U., Mende, S. B., and Angelopoulos, V.: Substorm onset observations by IMAGE-FUV, J. Geophys. Res., 109, A10304, doi:10.1029/2004JA010607, 2004.

Gaunt, C. T. and Coetzee, G.: Transformer failures in regions incorrectly considered to have low GIC-risk., IEEE Power Tech, Conference Paper 445, 2007.

Kappenman, J. G.: An overview of the impulsive geomagnetic field disturbances and power grid impacts associated with the violent Sun-Earth connection events of 29-31 October 2003 and a comparative evaluation with other contemporary storms., Space Weather, 3, SO8C01, doi:10.1029/2004SW000128, 2005.
Kappenman, J. G.: Geomagnetic Disturbances and Impacts upon Power System Operation, The Electric Power Engineering Handbook, edited by: Gigsby, L. L., CRC Press/IEEE Press, 2nd edn., 2007.

Koen, J.: Geomagnetically induced currents and their pressence in the Southern African electricity transmission network., $\mathrm{PhD}$ thesis, University of Cape Town, 2002.

Lehtinen, M. and Pirjola, R.: Currents produced in earthed conductor networks by geomagnetically-induced electric fields, Ann. Geophys., 4, 479-484, 1985.

Molinski, T. S.: Why utilities respect geomagnetically induced currents, J. Atmos. Terr. Phys., 64, 1765-1778, 2002.

NGDC: ftp://ftp.ngdc.noaa.gov/STP/GEOMAGNETIC_DATA/ INDICES/DST/, last access 6 March 2009.

Ngwira, C. M., Pulkkinen, A., McKinnell, L.-A., and Cilliers, P. J.: Improved modeling of geomagnetically induced currents in the South African power network, Space Weather, 40, S11004, doi: 10.1029/2008SW000408, 2008.

Rae, I. J., Mann, I. R., Murphy, K. R., Milling, D. K., Parent, A., Angelopoulous, V., Frey, H. U., Kale, A., Watt, C. . E. J., Mende, S. B., and Russell, C. T.: Timing and localization of ionospheric signatures associated with substorm expansion phase onset., J. Geophys. Res., 114, A00C09, doi:10.1029/2008JA013559, 2009.

Thomson, A. W. P., McKay, A. J., Clarke, E., and Reay, S. J.: Surface electric fields and geomagnetically induced currents in the Scottish Power grid during the 30 October 2003 geomagnetic storm, Space Weather, 3, S11002, doi:10.1029/2005SW000156, 2005.

Viljanen, A., Nevanlinna, H., Pajunpää, K., and Pulkkinen, A.: Time derivative of the horizontal geomagnetic field as an activity indicator, Ann. Geophys., 19, 1107-1118, 2001, http://www.ann-geophys.net/19/1107/2001/.

Viljanen, A., Tanskanen, E. I., and Pulkkinen, A.: Relation between substorm characteristics and rapid temporal variations of the ground magnetic field, Ann. Geophys., 24, 725-733, 2006, http://www.ann-geophys.net/24/725/2006/.

Wik, M., Viljanen, A., Pirjola, R., Pulkkinen, A., Wintoft, P., and Lundstedt, H.: Calculation of geomagnetically induced currents in the $400 \mathrm{kV}$ power grid in southern Sweden, Space Weather, 6 , S07005, doi:10.1029/2007SW000343, 2008. 